\title{
Biotemplate Assisted Nano Titania and Its Environmental Performance
}

\author{
N. Saikumari1 ${ }^{*}$, S. Monish Dev², S. Avinaash Dev³ \\ ${ }^{1}$ Science and Humanities, RMK College of Engineering and Technology, Chennai, India \\ ${ }^{2}$ Anna University, Chennai, India \\ ${ }^{3}$ RMKCET, Chennai, India \\ Email: *saikumarisudhakhar@gmail.com
}

How to cite this paper: Saikumari, N., Dev, S.M. and Dev, S.A. (2020) Biotemplate Assisted Nano Titania and Its Environmental Performance. Journal of Minerals and Materials Characterization and Engineering, 8, 459-471.

https://doi.org/10.4236/jmmce.2020.86029

Received: October 27, 2020

Accepted: November 27, 2020

Published: November 30, 2020

Copyright () 2020 by author(s) and Scientific Research Publishing Inc. This work is licensed under the Creative Commons Attribution International License (CC BY 4.0).

http://creativecommons.org/licenses/by/4.0/

\section{(c) (i) Open Access}

\begin{abstract}
Environmental sustainability apart from spoken at different levels needs to investigate the management of industrial activities in terms of eco-friendliness. It is well known that effluents from various industries become a major source of environmental degradation in particular water pollution. Thus water analysis report turns to be more significant, to determine the quality and standard of life maintained in a typical ecosystem. This study includes the analysis of physico-chemical factors of raw as well as treated water samples from Korattur Lake employing nano sized adsorbents like titania with tuned structural and morphological properties through organic plant extract. The XRD analysis, BET analysis, DRS-UV analysis, SEM and TEM analysis have been carried out and reported. The marked influence of leaf extract as a template is reflected in reduced crystallite size $(12.4 \mathrm{~nm})$ with maximum surface area 105 $\mathrm{m}^{2} / \mathrm{g}$ along with bathochromic shift of absorption edge. The usual indicators of contamination level at a given source namely Biological Oxygen Demand (BOD-85\%), Chemical Oxygen Demand (COD-94.5\%), Dissolved Oxygen (88\%), Total Suspended Solids (TSS-75.6\%), Electrical Conductivity (74.5\%), Chloride (89\%), Nitrate and Phosphate contents etc. were used to ascertain the efficiency of contaminants removal using tea leaf extract mediated nano titania. The reliability factor of the treatment process was found to be less than 1 , revealed the effectiveness and reliability of nano material.
\end{abstract}

\section{Graphical Abstract}

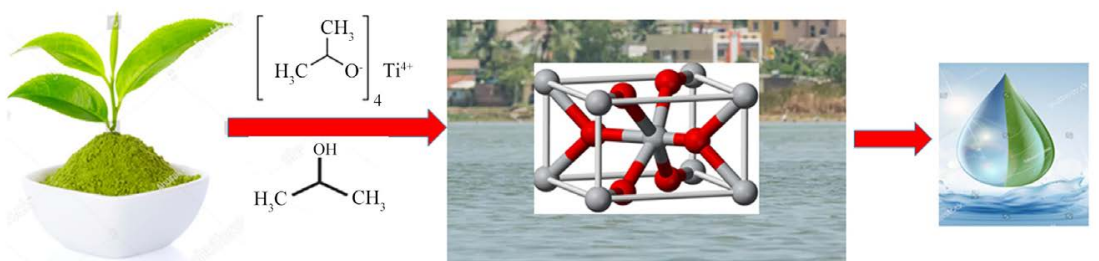




\section{Keywords}

Sustainability, Ecosystem, Pollution, Nano Titania, Plant Extract

\section{Highlights}

- Synthesis of mesoporous nano sized photo catalyst by one point synthesis under sol-gel technique.

- Use of bio templates in extending the absorption edge to a visible region apart from tuning crystalline and structural properties for superior photo catalysis.

- Exploring the performance of a synthesized catalyst in the water treatment of waste water from native ecosystem under solar irradiation.

\section{Introduction}

Water is one of the indispensable resources that is available on the earth and is also one of the primary needs of an individual at present. But due to various industrial, agricultural and domestic discharge of waste water into different water sources resulted in water exploitation and pollution, the availability of fresh water found to be rare commodity nowadays [1]. It is very important to know that industrial growth, human health, environmental enrichment, plant growth and sustainable development etc. are directly linked to quality of water, which is the vital concern of the mankind today. It is worldwide concern that lack of pure and safe water supply leads to ill health affecting human kind especially in developing countries. Increasing population, urbanization, mining, other agricultural and industrial activities followed by their immediate impacts deteriorate the surface and subsurface, thus polluting water on surface. The different forms of metabolic and physiological activities and life cycle of aquatic animals are greatly influenced by the polluted water and thus the analysis on physiochemical characteristics of water is found to be highly essential [2] [3] [4] [5].

River water is the chief water source meant for drinking, agriculture and engineering purpose both in rural and urban areas. The numerous chemicals used in the industries, pollutants like heavy metals, dyes and suspended solids in the form effluents discharged into rivers, continue to generate waste water having significant effect on flora and fauna [6]. Hence it is mandatory to monitor and confirm the standard of the same by regular evaluation of their physical, chemi$\mathrm{cal}$ and biological parameters through water treatment processes prior to their discharge. In this regard heterogeneous photocatalysis using semiconductor metal oxides as catalysts proved to be highly dominating among different water treatment techniques in removing pollutants from water and air without leaving any secondary pollutants [7].

Photocatalysis process among AOPs mainly employed in the field of effluent treatment from industries with the help of hydroxyl radicals being produced 
during the procedure [8]. Titania in the nano size is one of the promising photocatalysts employed to the greater extents in the recent decades being cost-effective, ease of production, less toxic and photo stable with desired band gap. But its poor visible light absorption along with low surface area restricted its applications in larger scale [9] that could be overcome by the controlled synthesis of titania either by doping with metal and non-metal or coupling with other metal oxides [10] [11]. To meet this requirement bio template assisted sol-gel mediated nano titania is proved to be clean, safe, eco-friendly, cost-effective and less toxic and yield titania with high superficial area, widespread pores and extensive morphologies [12]. In addition, to diminish the creation of harmful byproducts, green synthesis of the nano particles using bio materials were developed [13]. It can positively impact the nanomaterials thus produced either by removing or limiting the generation as well as usage of toxic substances [14].

In the present study, water sample is taken from Korattur lake also known as Vembu Pasumai Thittu of about 990 acres in Korattur, India which is one of the largest lake in western part of the city. The residents of Chennai have been benefiting from this source during the water scarcity but was found to be polluted by the continuous release of runoffs from the nearby domestic and commercial sources. The lake apart from reptiles and amphibians has a dwelling of common and rare birds like grey pelican, Asian open bill, grey heron, large egret, coot, purple swamp hen, common moorhen etc.

The current work is a unique initial attempt to examine the technical feasibility of photocatalytic effect of nano titania tuned by the addition of leaf extract as a bio template against the sample taken from Korattur lake. The experiments were carried out at ambient conditions taking into account the different parameters like $\mathrm{pH}$, catalyst dosage, light intensity and contact time on a pilot scale for further study. The nano titania catalyst was synthesized by simple, cheap one pot synthesis under sol-gel technique and characterized by XRD, BET, FTIR, DRS-UV, SEM and TEM analysis and found to be effective for normalizing water parameters, commercially and technically much affordable .

\section{Experiment}

\subsection{Chemicals Used}

Titanium tetra isopropoxide (TTIP, $99 \%$ pure) a precursor, Iso propanol (99\% pure) and Acetic acid were collected from Sigma Aldrich. $\mathrm{HCl}$ and $\mathrm{NaOH}$ were obtained from Sigma Aldrich. A lemon tea extract used as a bio template was purchased from supermarket and washed repeatedly two to three times with double distilled water.

\subsection{One Pot Synthesis of Nano Titania}

In $100 \mathrm{ml}$ beaker, $60 \mathrm{ml}$ of iso propanol was mixed with $9 \mathrm{ml}$ of TTIP and $30 \mathrm{ml}$ of $4 \%$ acetic acid and about $1 \mathrm{~g}$ of tea leaf extract. The mixture is subjected to continuous stirring for $1 \mathrm{~h}$ which was resulting in a homogeneous colloidal sol 
due to hydrolysis and condensation reactions. The suspension is left undisturbed for $10 \mathrm{~h}$ to get a gel, then dehydrated at $110^{\circ} \mathrm{C}$ for $4 \mathrm{~h}$ using oven. The dampness free powder obtained was calcined at $400^{\circ} \mathrm{C}$ for $4 \mathrm{~h}$ and stored and named as TNT.

\subsection{Characterization of Templated Nano Titania}

The XRD pattern for the phase analysis was obtained using X-ray diffractometer with $\mathrm{Cu} \mathrm{K} \alpha\left(\lambda=1.546 \mathrm{~A}^{\circ}\right)$ radiations in $2 \theta$ range from $20^{\circ}$ to $80^{\circ}$ with a scan rate of $2^{\circ}$ per minute at room temperature in order to assess their crystallite size and structural properties. A Perkin-Elmer spectrometer using $\mathrm{KBr}$ pellet technique was used to study FT-IR. About $20 \mathrm{mg}$ of the sample was made into a pellet along with special grade $\mathrm{KBr}$ using hydraulic press. The synthesized samples were subjected to scan within $4000-400 \mathrm{~cm}^{-1}$. DRS-UV spectral analysis of the sample was carried out using Schimadzu UV 2450 with $\mathrm{BaSO}_{4}$ as a standard. The band gap energy was calculated using Tauc equation (Tauc et al. 1966),

$$
(\alpha h \vartheta)=\operatorname{const}(h \vartheta-E g)
$$

where, $n$-type of electronic transition, $h \vartheta$-photon energy, $\alpha$-absorption co-efficient. The surface properties were analyzed using Quadrasorb Surface Analyzer. Scanning Electron Microscope (Quanta 200 ESEM) was used to study the morphology of the templated sample.

\subsection{Treatment of Sample Water Using Green Synthesized TNT}

\subsubsection{Sample Collection}

The raw water sample to be subjected for photocatalytic degradation using templated nano catalyst TNT was collected from the selected point of Korattur Lake in $1 \mathrm{~L}$ plastic bottle which was sterilized and previously rinsed with the same. The basic overall characteristics were analyzed in Swasthi Enviro Solutions Private Limited, Chennai and shown in Table 1. It is noted that most of the parameters like nitrate, phosphate, calcium contents etc. were found to be within the permissible level of IS10500:2012. The other parameters likely to be treated were subjected to photo catalysis by a synthesized catalyst TNT under optimized conditions of $\mathrm{pH}$, catalyst dosage, temperature etc.

Table 1. Water parameters of the sample from Korattur Lake.

\begin{tabular}{cccc}
\hline S.No. & Parameter & Unit & Concentration \\
\hline 1 & COD-chemical oxygen demand & $\mathrm{mg} / \mathrm{L}$ & 185 \\
2 & BOD-biological oxygen demand & $\mathrm{mg} / \mathrm{L}$ & 92 \\
3 & DO-dissolved oxygen & $\mathrm{mg} / \mathrm{L}$ & 4.2 \\
4 & $\mathrm{pH}$ & - & 8.5 \\
4 & TDS-total dissolved solids & $\mathrm{mg} / \mathrm{L}$ & 7000 \\
5 & EC-electrical conductivity & $\mu \mathrm{S} / \mathrm{cm}$ & 8500 \\
6 & chloride content $\left(\mathrm{Cl}^{-}\right)$ & $\mathrm{mg} / \mathrm{L}$ & 520 \\
\hline
\end{tabular}




\subsubsection{Photocatalytic Treatment of Sample Water}

To evaluate the efficacy of synthesized nano catalyst TNT towards the degradation of pollutants in sample water taken from Korattur Lake, $500 \mathrm{ml}$ of the sample without any alterations was transferred to $2 \mathrm{~L}$ wide mouthed petri dish made of borosilicate glass and exposed to direct sunlight. $\mathrm{HCl}$ and $\mathrm{NaOH}$ were used to adjust the $\mathrm{pH}$ of the sample water containing pollutants. The HTC make Digital Lux meter (model LX-101A) has been used to determine the intensity of sunlight in the month of April and May from 12 noon to $2 \mathrm{pm}$ and was found to be 1.25 $\times 10^{5}$. Before subjecting the suspension mixture to solar irradiation the experiment was carried out in the dark to equilibrate the adsorption of pollutants on the surface of TNT. The degradation of pollutants in the waste water was followed by regular withdrawal of samples at regular intervals from the dish and the variation in its concentration was monitored by Lambda 35, Perkin Elmer a spectrophotometer at wavelength $590 \mathrm{~nm}$.

\section{Results and Discussion}

\subsection{Characteristics of Green Synthesized and Calcined TNT}

Figure 1 shows the XRD pattern of templated titania TNT calcined at $400^{\circ} \mathrm{C}$, in which the peaks originated from (100), (004), (105), (301), (105), and (116) planes that of pure anatase phase were in fine agreement with JCPDS 21-1272 (the standard pattern of anatase phase) confirmed the formation of phase pure anatase titania [15]. The non-existence of peaks corresponding to $27.5^{\circ}$ and $30.8^{\circ}$ have shown the absence of rutile and brookite phases. Recording of noise level in the XRD diffractogram might be due to template particles on catalyst's surface. The crystallite size was calculated with respect to (101) plane $\left(\theta=25.1^{\circ}\right)$ with highest intensity using Debye Scherrer formula $\mathrm{D}=\mathrm{K} \lambda / \beta \operatorname{Cos} \theta$. The average crystallite size of TNT catalyst was calculated to be $12.4 \mathrm{~nm}$.

Figure 2 gives the FT-IR spectrum of raw template (3a), as synthesized (3b) and calcined (3c) TNT catalysts. FT-IR spectrum of fresh leaf extract has shown the peaks corresponding to stretching vibrations of poly phenols, carboxylic acid, poly saccharide, amino acid etc. at 1623, 1025, 1394 and $1025 \mathrm{~cm}^{-1}$ [16] and the peaks due to $\mathrm{O}-\mathrm{H}$, symmetric and asymmetric stretching vibrations of $\mathrm{CH}_{2}$, $\mathrm{CH}, \mathrm{C}=\mathrm{O}$ etc. at 3369, 2924, 2866, 1750 respectively [17]. In as synthesized TNT (curve b) and calcined TNT (curve c), peaks due to the presence of $-\mathrm{OH}$ and other functional groups were shifted to lower number showing the weak hydrogen bond interaction between hydroxyl hydrogen and oxygen of titania on the surface [18]. The absence of respective peaks of an organic leaf extract in the case of calcined TNT (curve c) clearly indicated the removal of template from the catalyst and the broad absorption band at $400-750 \mathrm{~cm}^{-1}$ established the formation of $\mathrm{Ti}-\mathrm{O}-\mathrm{Ti}$ linage characteristic as that of titania [19].

Figure 3 shows the $\mathrm{N}_{2}$ adsorption-desorption isotherm of TNT sample, the specific surface area was observed to be $105 \mathrm{~m}^{2} / \mathrm{g}$. The isotherms match with the type III adsorption pattern confirming capillary condensation of the particles on the surface of nano titania. The results of surface analysis are in good agreement 
with the report that reduced crystallite surface would enhance the photocatalytic activity of a catalyst [20]. From BJH analysis, the average pore size of the catalyst TNT is $9.21 \mathrm{~nm}$. Thus a template has played a critical role in tuning surface area and pore size distribution uniformly to support the overall photocatalytic waste water treatment.

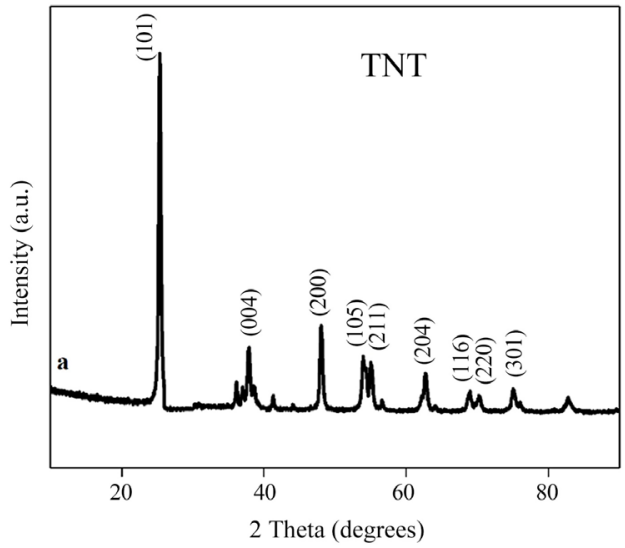

Figure 1. XRD pattern of Calcined TNT.

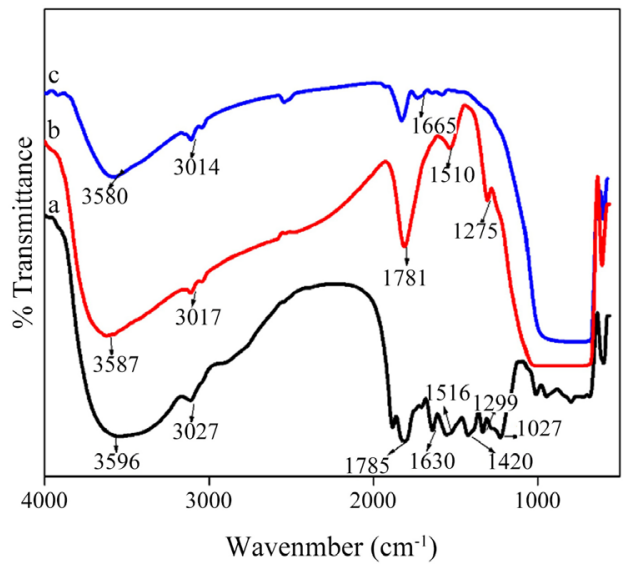

Figure 2. FTIR spectrum of (a) tea leaf template (b) as-synthesized TNT (c) calcined TNT.
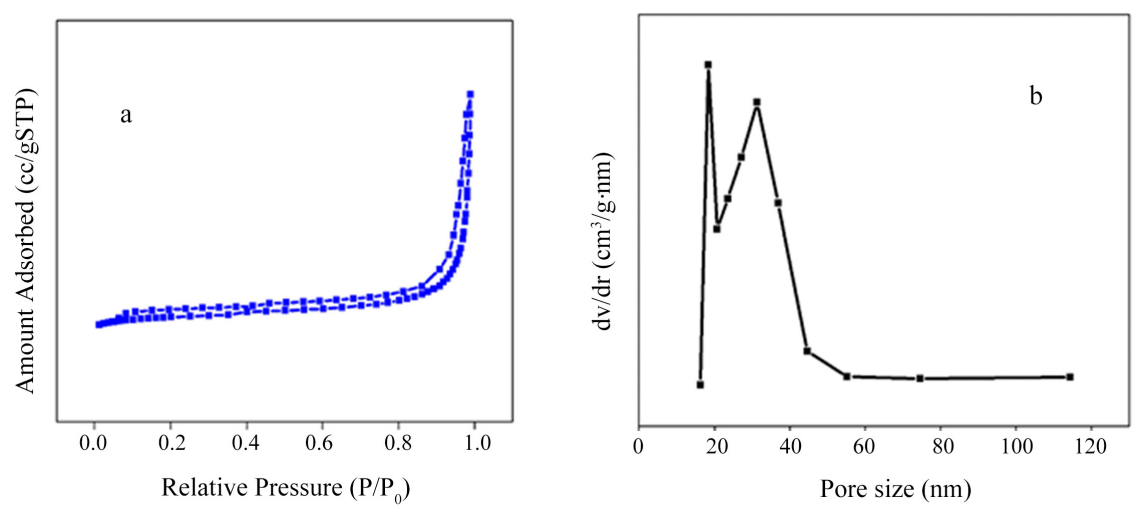

Figure 3. (a) N2 Adsorption-Desorption (b) Poresize Distribution analysis of calcined TNT. 
DRS-UV Visible spectra (Figure 4(a)) clearly has shown a bathochromic shift i.e. the shifting of absorption band to visible region corresponding to appearance of absorption edge at $424 \mathrm{~nm}$. Also the band gap energy was found to be $2.83 \mathrm{eV}$, from the Tauc plot (Figure 4(b)). The above facts clearly illustrated the fine-tuning of TNT to act as a active photo catalyst in the visible UV region and could be employed as a water treatment agent successfully.

Figure 5(a) shows the results of SEM analysis of calcined TNT. The finely dispersed nano particles with moderate agglomeration and irregularities in the image of TNT confirmed the presence of widespread particles that would increase the adherence and interaction of the pollutant molecules in the sample water with the titania catalyst [21]. Thus it is evident that lowering agglomeration reduces the crystallite size of the catalyst as observed in the BET surface area analysis. It is clearly noted that all the templated titania particles with grains of unequal sizes and uniformly distributed voids on the surface may bring out greater adsorption and hence better photo catalytic activity. EDS analysis of TNT (Figure 5(b)) pattern clearly indicated the presence of only Ti and $\mathrm{O}$ and the non-existence of other elements, thus confirmed the purity and complete elimination of a leaf extract during the calcination of TNT at $400^{\circ} \mathrm{C}$.
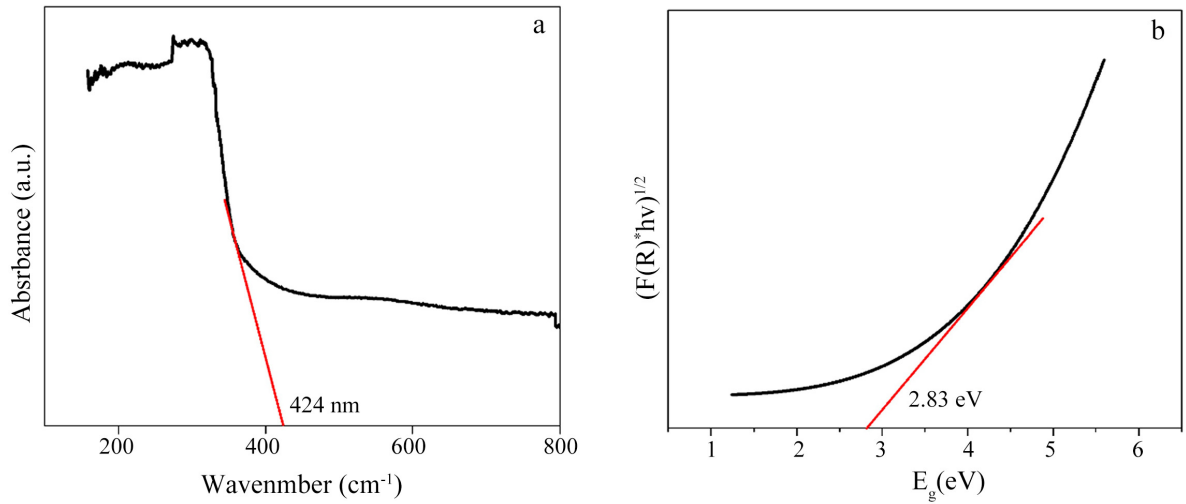

Figure 4. (a) DRS-UV and (b) Tauc plot of calcined TNT.
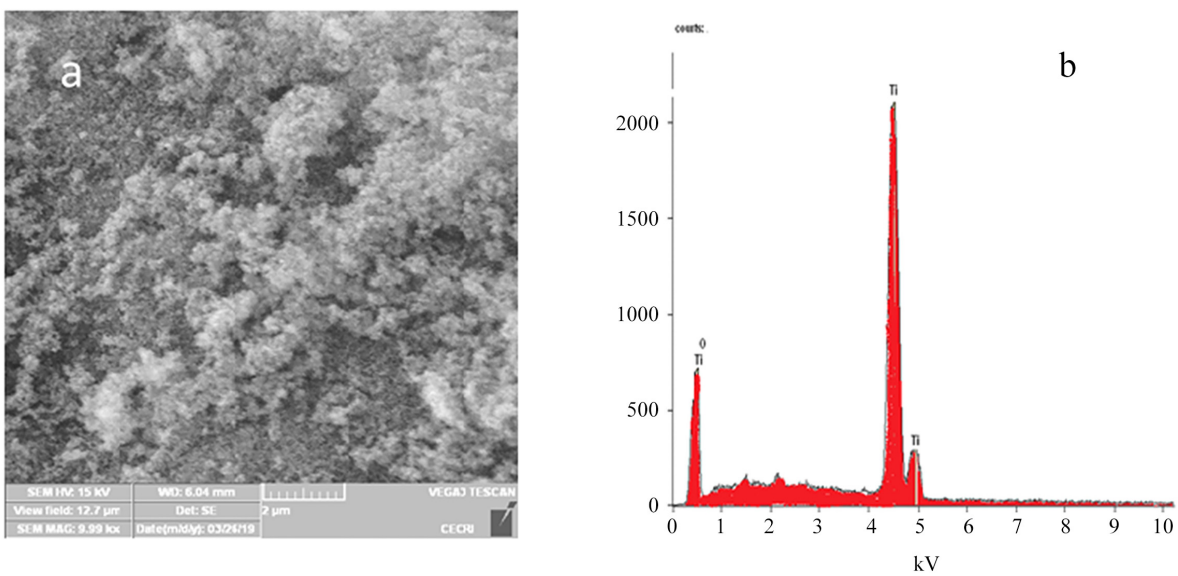

Figure 5. (a) SEM micrograph and (b) EDAX analysis of calcined TNT. 
Figure 6(a) gives the TEM image, the uniform distribution of nano particles in Calcined TNT. The crystallite size of the nano particles was ranging from 12.2 - $14.6 \mathrm{~nm}$, and holds good with the average crystallite size of TNT reported in $\mathrm{XRD}$ analysis. The presence of particles of lowered agglomeration and indefinite shape showed the impact of biotemplate during the synthesis on the grain growth and morphology of TNT, a catalyst. Highly resolved lattice fringes and well defined ring pattern of SAED image (Figure 6(b)) that were of typical anatase phase clearly substantiated the purity and crystallinity of synthesized and calcined nano catalyst TNT [22].

\subsection{Removal Efficiency of Water Parameters by Green Synthesized and Calcined TNT}

To study the photo catalytic efficiency performance of the synthesized nano catalyst TNT, the physico chemical properties of raw (Table 1) and treated waste water sample were compared and analyzed. From the data given in Table 1, the values of various parameters recorded clearly recommended the requisite of water treatment of the sample as some values reported were higher than the permissible level as per water pollution control board, Tamilnadu, due to discharge of nearby industrial and domestic effleunts. The reduction efficiency of the catalyst synthesized and used in this study, namely TNT was given by the equation,

$$
\text { Removal efficiency }=\left(\mathrm{A}-\mathrm{A}^{\prime}\right) / \mathrm{A} \times 100 \text {, }
$$

where

$A=$ Concentration of waste water before treatment and $A^{\prime}=$ Concentration of waste water after treatment.

\subsubsection{Chemical Oxygen Demand-COD, Biological Oxygen Demand-BOD, and Dissolved Oxygen-DO}

COD is the quntity of oxygen required to oxidise an organic matter present in the water which is responsible for the contamination, and was determined titrimetric method using a powerful oxidizing substance. It is usually more than the value of $\mathrm{BOD}$ as few organic pollutants which are resistant to biological oxidation could undergo oxidation chemically. COD calaculations are made quickly whereas BOD estimation used to take minimum 5 days [23]. Th COD of raw sample was $126 \mathrm{mg} / \mathrm{L}$ while $94.5 \%$ reduction of the same parameter after the photocatalytic treatment was realized.

BOD is the sum of oxygen required for oxidizing organic pollutants microbially, is used as a standard test to examine the efficiency of the treatment method adopted and the level of toxicity in the effluent. BOD is directly associted with DO, higher is a BOD level, greater is the reduction of available oxygen which leads to more deaths of aquatic organisms [24]. The photocatalytic treatment using TNT brought about $85 \%$ reduction of BOD with respect to the reported value of raw sample as $80 \mathrm{mg} / \mathrm{L}$. The value of BOD/COD waste water is used as an index, which is designed to estimate the presence as well as the nature of biodegradable chemical impurities in the waste water in turn applied to predict the suitable water treatment techniques [25]. 

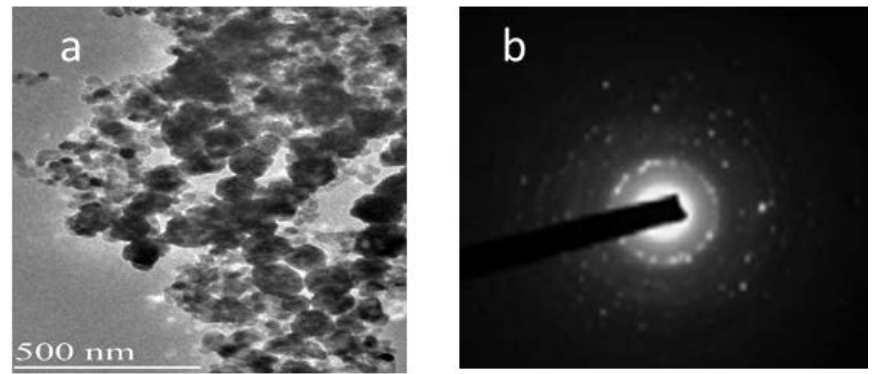

Figure 6. (a) TEM analysis and (b) SAED pattern of TNT catalyst.

DO-Dissolved Oxygen is one of the vital parameter of water parameters and is served as a tool to study the condition of an ecosystem [26]. The amount of dissolved oxygen in water is partially dependent of different activities occurring in it physically, chemically and biologically. The dissolved oxygen content in water would be directly proportional to pressure and is inverse to temperature and salinity as reported by the scientists [27]. Prior to the photocatalytic treatment, the amount of dissolved oxygen was about $4.2 \mathrm{mg} / \mathrm{L}$, and after the treatment it was increased to $7.9 \mathrm{mg} / \mathrm{L}$ and nearly $88 \%$ efficacy has been realized. Dissolved Oxygen content in water varies inverse to BOD/COD as reported [28]. During the visible light photocatalysis, the various organic pollutants were decomposed effectively when they come into contact with TNT catalyst's surface as shown in Figure 7 [29].

\subsubsection{Reduction of TDS-Total Dissolved Solids, EC-Electrical Conductivity and Chloride Content in Waste Water}

TDS is a estimation of dissolution of chemical substances, inorganic and organic impurities in water [26]. Though there is no particular standard to have TDS in water, it should not go beyond $1500 \mathrm{mg} / \mathrm{L}$ for irrigative purposes and domestic uses. Excess TDS in water may lead to hard scaling in boilers, pipes and other household appliances [30]. Photocatalytic treatment of waste water using a nano catalyst TNT had brought about $75.6 \%$ reduction efficiency and thus the water became free from suspended solids. This reduced concentration of TDS could control the dehydration of aquatic animals [30].

Water sample of particular electrical conductivity-EC varies directly to dissolved solids content or in other words it is the measure of dissolved solid impurities [30]. Higher value of EC is also the indication of richness of inorganic contents in the waste water because of chemicals like additives, thinners and pigments in the form of effluents from industries. It is highly necessary to treat waster with high EC content as it could easily cause imbalance for aquatic organisms by reducing the dissolved oxygen content [31]. By using TNT the decrease in EC was reported around $74.5 \%$ at the end of photocatalytic treatment under solar irradiation.

The chloride content in any water source should not exceed $350 \mathrm{mg} / \mathrm{L}$ as per WHO recommendation [32] as it would threaten the sustainability of food resources in an ecosystem in turn that might pose a high danger to living species, 
their growth and also reproduction [31]. Bio-accumulation and the tenacity of chloride in waste water in high concentration may be due to the presence of chlorinated resins, chemical compounds like PVC, alkyl benzyl ammonium chloride etc. in the effluents of industries nearby. About $89 \%$ of reduction efficiency has been shown by TNT over the adsorption of chloride impurities. Thus the overall reduction of TDS, EC and chloride content as shown in Figure 8 directly meant to conserve aquatic organisms and water quality, substantiate the photocatalytic efficiency of TNT in producing $\mathrm{OH}$ and $\mathrm{O}^{2-}$ to decompose organic pollutants in waste water into $\mathrm{CO}_{2}$ and $\mathrm{H}_{2} \mathrm{O}$ [33].

\section{Conclusion}

This present work aimed forward to establish the photocatalytic activity of nano titania TNT, produced by simple sol-gel mediated one pot synthesis meant to eliminate the organic toxins present in the effluent from industries. The various data obtained during the removal of contaminants used to interpret the photo stability of the synthesized catalyst as well as adsorption behavior of impurities on TNT surface. Thus mesoporous phase pure titania catalyst with high surface area $\left(105 \mathrm{~m}^{2} / \mathrm{g}\right)$, moderate porosity along with bathochromic shift showed its

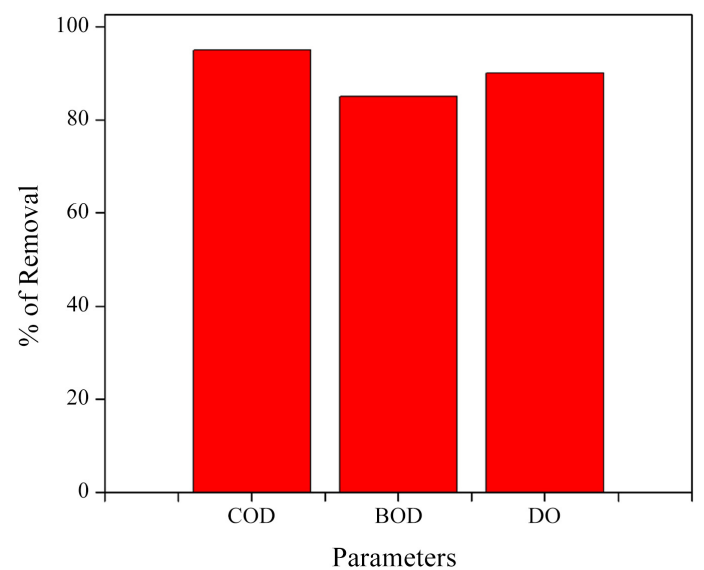

Figure 7. Removal efficiency of TNT on COD, BOD and DO contents.

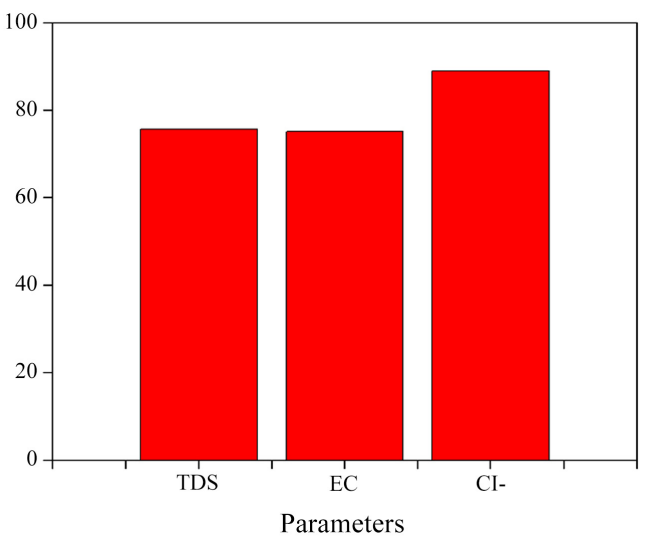

Figure 8. Removal efficiency of TNT on TDS, EC and $\mathrm{Cl}^{-}$contents. 
maximum efficiency in the removal of pollutants from waste water drawn from well-known key ecosystem. Thus the role of biotemplate in shifting absorption edge of synthesized and calcined TNT to $424 \mathrm{~nm}$ was quite evident through its photocatalytic reduction and the removal efficiencies under solar irradiation compared to commercially available titania as discussed in earlier studies. This performance could be extended to large scale and employed as a better tool in the field of pollution abatement on profitable scale.

\section{Acknowledgements}

N. Saikumari thanks the Management, RMK Management, Chennai for their moral support to carry out the analysis and complete this work successfully.

\section{Conflicts of Interest}

The authors declare no conflicts of interest regarding the publication of this paper.

\section{References}

[1] Usharani, K., Umarani, K., Ayyasamy, P.M., Shanthi, K. and Lakshmana, P.P. (2010) Physico-Chemical and Bacteriological Characteristics of Noyyal River and Ground Water Quality of Perur, India. Journal of Applied Sciences and Environmental Management, 14, 29-35. https://doi.org/10.4314/jasem.v14i2.57830

[2] Srinivasan, V. (2013) Analysis of Static and Dynamic Load on Hydrostatic Bearing with Variable Viscosity and Pressure. Indian Journal of Science and Technology, 6, 4777-4782. https://doi.org/10.17485/ijst/2013/v6isp6.11

[3] Srinivasan, V. (2014) Optimizing Air Traffic Conflict and Congestion Using Genetic Algorithm. Middle East Journal of Scientific Research, 20, 456-461.

[4] Praveen, R. and Achudhan, M. (2014) Optimization of Jute Composite as a Noise Retardant Material. International Journal of Applied Engineering Research, 9, 7627-7632.

[5] Kumar, G.R., Achudhan, M. and Srinivasa Rao, G. (2014) Studies on Corrosion Behaviour of Borated Stainless Steel (304B) Welds. International Journal of Applied Engineering Research, 9, 7767-7772.

[6] Ahmed, S.N. and Haider, W. (2018) Heterogeneous Photocatalysis and Its Potential Applications in Water and Wastewater Treatment: A Review. Nanotechnology, 29, Article ID: 342001. https://doi.org/10.1088/1361-6528/aac6ea

[7] Bellardita, M., Fiorenza, R., D’Urso, L., Spitaleri, L., Gulino, A., Compagnini, G., Scirè, S. and Palmisano, L. (2020) Exploring the Photothermocatalytic Performance of Brookite $\mathrm{TiO}_{2}-\mathrm{CeO}_{2}$ Composites. Catalysts, 10, 765. https://doi.org/10.3390/catal10070765

[8] Somvanshi, S.B. and Kharat, P.B. (2020) Nanocatalyst: A Brief Review on Synthesis to Applications. Journal of Physics. Conference Series, 1644, Article ID: 012046. https://doi.org/10.1088/1742-6596/1644/1/012046

[9] Pellegrino, F., Pellutie, L., Sordello, F., Minero, C., Ortel, E., Hodoroaba, V.D. and Maurino, V. (2017) Influence of Agglomeration and Aggregation on the Photocatalytic Activity of $\mathrm{TiO}_{2}$ Nanoparticles. Applied Catalysis B: Environmental, 216, 80-87. https://doi.org/10.1016/j.apcatb.2017.05.046 
[10] Saravanakkumar, D., Abou Oualid, H., Brahmi, Y., Ayeshamariam, A., Karunanaithy, M., Mohamed Saleem, A., Kaviyarasu, K., Sivaranjani, S. and Jayachandran, M. (2019) Synthesis and Characterization of $\mathrm{CuO} / \mathrm{ZnO} / \mathrm{CNTs}$ Thin Films on Copper Substrate and Its Photocatalytic Applications. OpenNano, 4, Article ID: 100025. https://doi.org/10.1016/j.onano.2018.11.001

[11] Kinoshita, M., Kamizato, T. and Shimoyama, Y. (2018) Effect of Precursor Structure on Mixed-Crystal Phase Titanium Oxide Synthesized by Sol-Gel Reaction in Supercritical Carbon Dioxide. The Journal of Supercritical Fluids, 138, 193-199. https://doi.org/10.1016/j.supflu.2018.04.017

[12] Shreya, M.K., Indhumathi, C., Rajarajeswari, G.R., Ashokkumar, V. and Preethi, T. (2020) Facile Green Route Sol-Gel Synthesis of Nano-Titania Using Bio-Waste Materials as Templates. Clean Technologies and Environmental Policy, 22, 269-277. https://doi.org/10.1007/s10098-020-01928-6

[13] Saritha, V., Agastian, P., Mariadhas Valan, A., Al-Dhabi, N.A., Abdul-Kareem, M., Kaviyarasu, K., Balasubramani, R., Soon, W.C. and Arokiyaraj, S. (2019) Rapid Biosynthesis and Characterization of Silver Nanoparticles from the Leaf Extract of Tropaeolum majus L. and Its Enhanced In-Vitro Antibacterial, Antifungal, Antioxidant and Anticancer Properties. Journal of Photochemistry and Photobiology B: Biology, 191, 65-74. https://doi.org/10.1016/j.jphotobiol.2018.12.010

[14] Bindu, T., Scholastica, M., Vithiya, B., Augustine Arul Prasad, T., Mohamed, S.B., Maria Magdalane, C., Kaviyarasu, K. and Maaza, M. (2019) Antioxidant and Photocatalytic Activity of Aqueous Leaf Extract Mediated Green Synthesis of Silver Nanoparticles Using Passiflora edulis f. flavicarpa. Journal of Nanoscience and Nanotechnology, 19, 2640-2648. https://doi.org/10.1166/jnn.2019.16025

[15] Preeti, T., Abarna, B. and Rajarajeswari, G.R. (2014) Influence of Chitosan-PEG Binary Template on the Crystallite Characteristics of Sol-Gel Synthesized Meso Porous Nano-Titania Photo Catalyst. Applied Surface Science, 317, 90-97.

https://doi.org/10.1016/j.apsusc.2014.07.190

[16] Senthil Kumar, S.R. and Sivakumar, T. (2014) Green Tea Mediated Synthesis of Zn0 Nano Particles and Study on Their Antimicrobial Activities. International Journal of Pharmacy and Pharmaceutical Sciences, 6, 461-465.

[17] Lin, Y.-S., Tsay, Y.-J., Tsay, J.-S. and Lin, J.-K. (2003) Factors Affecting the Levels of Tea Polyphenols and Caffeine in Tea Leaves. Journal of Agricultural and Food Chemistry, 51, 1864-1873. https://doi.org/10.1021/jf021066b

[18] Zhang, W., Dehghani-Sanij, A. and Blackburn, R.S. (2008) IR Study on Hydrogen Bonding in Epoxy Resin-Silica Nanocomposites. Progress in Natural Science, 18, 801-805. https://doi.org/10.1016/j.pnsc.2008.01.024

[19] Kumar, P.M., Badrinarayanan, S. and Sastry, M. (2000) Nanocrystalline $\mathrm{TiO}_{2}$ Studied by Optical, FTIR and X-Ray Photoelectron Spectroscopy: Correlation to Presence of Surface States. Thin Solid Films, 358, 122-130.

https://doi.org/10.1016/S0040-6090(99)00722-1

[20] Ramimoghadam, D., Bagheri, S. and Bee Abd Hamid, S. (2014) Biotemplated Synthesis of Anatase Titanium Dioxide Nanoparticles via Lignocellulosic Waste Material. BioMed Research International, 2014, Article ID: 205636. https://doi.org/10.1155/2014/205636

[21] Mukhlish, M.Z.B., Najnin, F., Rahman, M.M. and Uddin, M.J. (2013) Photocatalytic Degradation of Different Dyes Using $\mathrm{TiO}_{2}$ with High Surface Area-A Kinetic Study. Journal of Scientific Research, 5, 301-314. https://doi.org/10.3329/jsr.v5i2.11641

[22] Saranya, K.S., Vellora Thekkae Padil, V., Senan, C., Pilankatta, R., Saranya, K., 
George, B., Wacławek, S. and Černík, M. (2018) Green Synthesis of High Temperature Stable Anatase Titanium Dioxide Nanoparticles Using Gum Kondagogu: Characterization and Solar Driven Photocatalytic Degradation of Organic Dye. Nanomaterials, 8, 1002. https://doi.org/10.3390/nano8121002

[23] Aniyikaiye, T.E., Oluseyi, T., Odiyo, J.O. and Edokpayi, J.N. (2019) Physico-Chemical Analysis of Wastewater Discharge from Selected Paint Industries in Lagos, Nigeria. International Journal of Environmental Research and Public Health, 16, 1235. https://doi.org/10.3390/ijerph16071235

[24] Rachna, B. and Disha, J. (2016) Water Quality Assessment of Lake Water: A Review. Sustain. Sustainable Water Resources Management, 2, 161-173. https://doi.org/10.1007/s40899-015-0014-7

[25] Abdallaa, K.Z. and Hammam, G. (2014) Correlation between Biochemical Oxygen Demand and Chemical Oxygen Demand for Various Wastewater Treatment Plants in Egypt to Obtain the Biodegradability Indices. International Journal of Sciences. Basic and Applied Research, 13, 42-48.

[26] Narragansett Bay Estuary Program (2017) Chapter 15: Dissolved Oxygen. State of Narragansett Bay and Its Watershed, Narragansett Bay Estuary Program, Providence, 276-296.

[27] Julian, K.T., Marianne, S. and Shaun, R. (2018) Contaminated Groundwater Sampling and Quality Control of Water Analyses. In: De Vivo, B., Belkin, H.E. and Lima, A., Eds., Environmental Geochemistry, 2nd Edition, British Geological Survey, Nottingham, 25-45. https://doi.org/10.1016/B978-0-444-63763-5.00004-5

[28] Edokpayi, J.N., Odiyo, J.O. and Durowoju, O.S. (2017) Chapter 18: Impact of Wastewater on Surface Water Quality in Developing Countries: A Case Study of South Africa. In: Tutu, H., Ed., Water Quality, IntechOpen, Rijeka, 401-416.

[29] Daviđsdóttir, S., Soyama, J., Dirscherl, S. and Schou, C.J. (2011) The European Corrosion Congress, 2011. Proceedings of European Corrosion Congress 2011, Stockholm, Vol. 1, 4-8.

[30] Uwidia, I.E. and Ukulu, H.S. (2013) Studies on Electrical Conductivity and Total Dissolved Solids. Concentration in Raw Domestic Wastewater Obtained from an Estate in Warri, Nigeria. Greener Journal of Physics and Natural Sciences, 3, 110-114. https://doi.org/10.5281/zenodo.3443966

[31] Imo, C.I., Nwakuba, N.R., Asoegwu, S.N. and Okereke, N.A.A. (2017) Impact of Brewery Effluents on Surface Water Quality in Nigeria: A Review. Journal of Chemical Research, 2, 101-113.

[32] World Health Organization (2006) A Compendium of Standards for Wastewater Reuse in the Eastern Mediterranean Region. Regional Office for the Eastern Mediterranean Regional Centre for Environmental Health Activities, Los Angeles, 1-19.

[33] Haque, M.M., Bahnemann, D. and Muneer, M. (2012) Photocatalytic Degradation of Organic Pollutants: Mechanisms and Kinetics, Organic Pollutants, IntechOpen, 293-326. 